\title{
A three-phase heuristic approach to solve an integrated cell formation and production planning problem
}

\author{
Amir Saman Kheirkhah ${ }^{a}$ and Alireza Ghajari ${ }^{\mathbf{a}^{*}}$
}

${ }^{a}$ Department of Industrial Engineering, School of Engineering, Bu-ali Sina University, Hamedan, Iran

\begin{tabular}{l}
\hline C H R O N I C L E \\
\hline Article history: \\
Received March 2, 2017 \\
Received in revised format June \\
10,2017 \\
Accepted July 172017 \\
Available online \\
July 182017 \\
\hline Keywords: \\
Cellular Manufacturing \\
System (CMS) \\
Production Planning (PP) \\
Production line balancing \\
Backorder \\
Heuristic algorithm
\end{tabular}

\section{Introduction}

In the Group Technology (GT) similarity between part types is the basis of production design and planning. Cellular Manufacturing (CM) is an industrial application of GT that has been employed by numerous firms in recent decades. Shorter product life-cycles and a shift to demands for mid-volume and mid-variety product mixes force producers to improve efficiency and productivity of their activities and production process. According to Wemmerlov and Hyer (1989), Job shops and flow lines cannot provide the efficiency and flexibility to adapt to such needs. Cellular manufacturing systems (CMSs) have emerged to cope with such production requirements and have been implemented with favorable results. It takes advantages of both flow shops and job shops with a lower level of cycle time than job shops and a higher level of flexibility and job satisfaction than flow shops. The major advantages and

\footnotetext{
* Corresponding author. Tel.:+988138292505, Fax: +988138292637

E-mail address: alirezaghajari.ag@gmail.com (A. Ghajari)

(C) 2018 Growing Science Ltd. All rights reserved.

doi: $10.5267 / j . u s c m .2017 .7 .001$ 
disadvantages of CMSs are explained in different resources such as Wemmerlov and Johnson (1997), Askin and Estrada (1999) and Suer and Ortega (1996).

Design and implementation of an effective CMS involve many issues that cell formation (CF) is the first and the most important step that can be classified into static and dynamic (Raminfar et al., 2013). In dynamic environment, each period has a different product mix and part demand. In reality, production quantity may not be equal to the demand and should be determined through production plannig (PP) decisions in order to determine the number and type of machines to be installed in manufacturing cells (Mahdavi et al., 2010). Consequently, the manufactured cells should be reconfigured in each period.

This paper presents an integrated mathematical model of CF and PP with several design features under a deterministic environment. The CF problem is an NP-hard problem but the integration of the CMS and PP makes the problem very complex and computationally hard (Tavakkoli-Moghaddam et al., 2008). Using exact (optimum) algorithms for the problem takes a long time and in some cases, it is impossible to reach optimality. Therefore the use of heuristic or meta heuristic algorithms is inevitable. In this study, an efficient heuristic algorithm is developed to solve the problem and to find the near optimal solutions. The efficiency of the algorithm is verified in terms of the objective function values and computational times by comparing with the optimal solutions.

One of the main applications of the developed model is in electronics industry that several production lines are utilized to produce and assemble the electronic parts and the circuit boards. The process includes fabrication line, insertion line, soldering area, assembly and packaging line. Variety of part types and their similarities are the main attributes in this industry. Each cell contains equipment that can be used for different operations after modification. To improve the productivity, the multi-product line balancing problem should be solved. On the other hand, machine replication is not possible or it is the last alternative to solve the problem because of the equipment high purchasing cost.

The rest of the paper is organized as follows: Literature related to the integrated CMS and PP is reviewed in Section 2. The problem is explained in Section 3 including definition, mathematical model, contributions and linearization. Section 4 explains the proposed three-phase approach. Then numerical example and computational results are reported. Finally, the main conclusion and future research are given in Section 6.

\section{Literature Review}

Research in CMS has been extensive during the last three decades. Although most studies have developed CF problem, some studies try to integrate CF problem with other issues such as PP. An integrated approach for production and inventory planning in a CM environment was developed by Chen (2001) and a decomposition-based heuristic algorithm was presented to solve the problem. Chen and Cao (2004) integrated PP and CMS to minimize the related costs and solved the resulted model by tabu search based procedure. Defersha and Chen (2008) developed a comprehensive mathematical model for dynamic manufacturing $\mathrm{CF}$ with the impact of lot size on product quality. They also developed a simulated annealing algorithm for dynamic system reconfiguration. Safaei and TavakkoliMoghadam (2009) integrated CF and PP problem with the emphasize on the effect of the trade-off between production and outsourcing costs on the reconfiguration of the cells in CMSs. Ahkioon et al. (2009a) presented a mixed integer non-linear model in CMS design with PP that attempts to minimize machine, material handling, and system reconfiguration costs in an integrated manner. Ahkioon et al. (2009b) also published another work that introduced routing flexibility in the system by the formation of alternate contingency process routings in addition to alternate main process routings for all part types.

Mahdavi et al. (2010) developed a model that integrates CF and PP in a dynamic CMS that considers worker assignments. Sarayloo and Tavakkoli-Moghaddam (2010) used Imperialistic Competitive Algorithm to solve dynamic CF problem with PP. Mahdavi et al. (2011) presented a fuzzy goal 
programming based approach for solving a multi-objective mathematical model of CF and PP in a dynamic virtual CMS considering worker flexibility. Saxena and Jain (2011) presented a comprehensive mixed integer programming model including cutting tooling requirements that integrates CF and PP. Rafiee et al. (2011) presented a comprehensive mathematical model for integrated CF and inventory lot sizing problem. Javadian et al. (2011) proposed a multi-objective dynamic CF problem where objective functions minimize total costs and total cell load variation, respectively. Khaksar-Haghani et al. (2011) developed a mathematical model by considering cell construction and cell unemployment costs. Soolaki (2012) presented a mathematical model for the design of CF in dynamic CMS based on PP and worker assignment.

Tavakkoli-Moghaddam et al. (2013) developed a robust optimization approach under uncertainty of parts processing time. Paydar et al. (2013) presented a comprehensive integer linear programming model with several design features including intra-cell layout. Raminfar et al. (2013) proposed a mixed integer non-linear programming model and used group capability index (GCI) as a measure to evaluate and verified the performance of the proposed model. Rabbani et al. (2014) developed a bi-objective mixed integer programming model to solve CF and PP, simultaneously. They used machine modification feature. Aghajani et al. (2014) presented a non-linear mixed integer mathematical model that integrates CF and PP, and solved by linearization. Shirazi et al. (2014) developed a multi-objective model that integrates CF, group layout, and PP as three interrelated decisions involved in the design of a CMS and used an archived multi-objective simulated annealing (AMOSA) algorithm to find Paretooptimal solutions.

Aghajani-Delavar et al. (2014) presented a new mathematical model for integrated dynamic CMS and PP that forms the manufacturing cells and determines the quantity of machine and movements during each period of time. Ghodsi et al. (2015) developed a multi-objective mathematical model to create stable CMS in order to minimize the costs of system establishment in addition to optimizing the environmental impacts of the manufacturing system. The model is seeking for a solution to create a manufacturing system in which all factors such as producers, the environment, workers and other are beneficiaries. Sakhaii et al. (2016) developed a robust optimization approach for a new integrated mixed integer linear programming model with unreliable machines. Aljuneidi and Bulgak (2016) presented a comprehensive mathematical model for the design and analysis of dynamic CMS that considers several manufacturing attributes such as the available time for workers, worker assignments, and machine procurement. Deep and Singh (2016) proposed an integrated mathematical model of multi-period CF and part operation tradeoff in a dynamic CMS with emphasize on the production flexibility. Khannan et al. (2016) developed CMS model with dynamic lot size material handling.

The goal of this paper is to present an effective heuristic to solve an integrated dynamic CMS and PP with important design attributes such as workload balance among cells and machines. Due to the numerous researches implemented in the CMS topics, we reviewed the important and recent literature related to the both CF and PP problems.

\section{Problem formulation}

\subsection{Assumptions}

The model is formulated under the following assumptions.

1. All parts are available to process at the beginning of the planning period.

2. Part demands in each period for each part type are independent and deterministic.

3. Different routes within the same cell or even in different cells can be used to produce needed quantity of the parts (lot splitting).

4. The inventory holding and backorder are considered with known unit costs. Thus, the demand for a part in a given period can be satisfied in the preceding or succeeding periods.

5. The processing time for all operations on different machine types are known and deterministic. 
6. All operations of part types must be processed and time needed for each unit is equal to bottleneck station.

7. All the machines are available at the beginning of the first period and purchasing a new machine is not allowed in planning horizon.

8. Capacity of each machine type is known and deterministic.

9. There are several machines of each type with identical duplicates to satisfy capacity requirements.

10. All machine types are assumed to be multipurpose. Thus, each machine type can perform one or more operations. In the same manner, each operation of a part type can be performed on different machine types with different processing times (alternative process routings).

11. Cells are independent, then inter-cell movements are not allowed.

12. Intra-cell part movement cost is based on distance between machines (one unit for two subsequent operations) and production quantity.

13. The upper and lower bound of cell size are known.

14. Machine relocation is performed between periods and it requires zero time.

15. Material handling devices are assumed to carry only one part at a time.

16. Relocation cost of each machine type from one cell/depot to another between periods is known.

17. Setup time of each machine is known and setup cost is calculated based on setup time and a common setup cost per time unit.

18. Operating cost of each machine type is known.

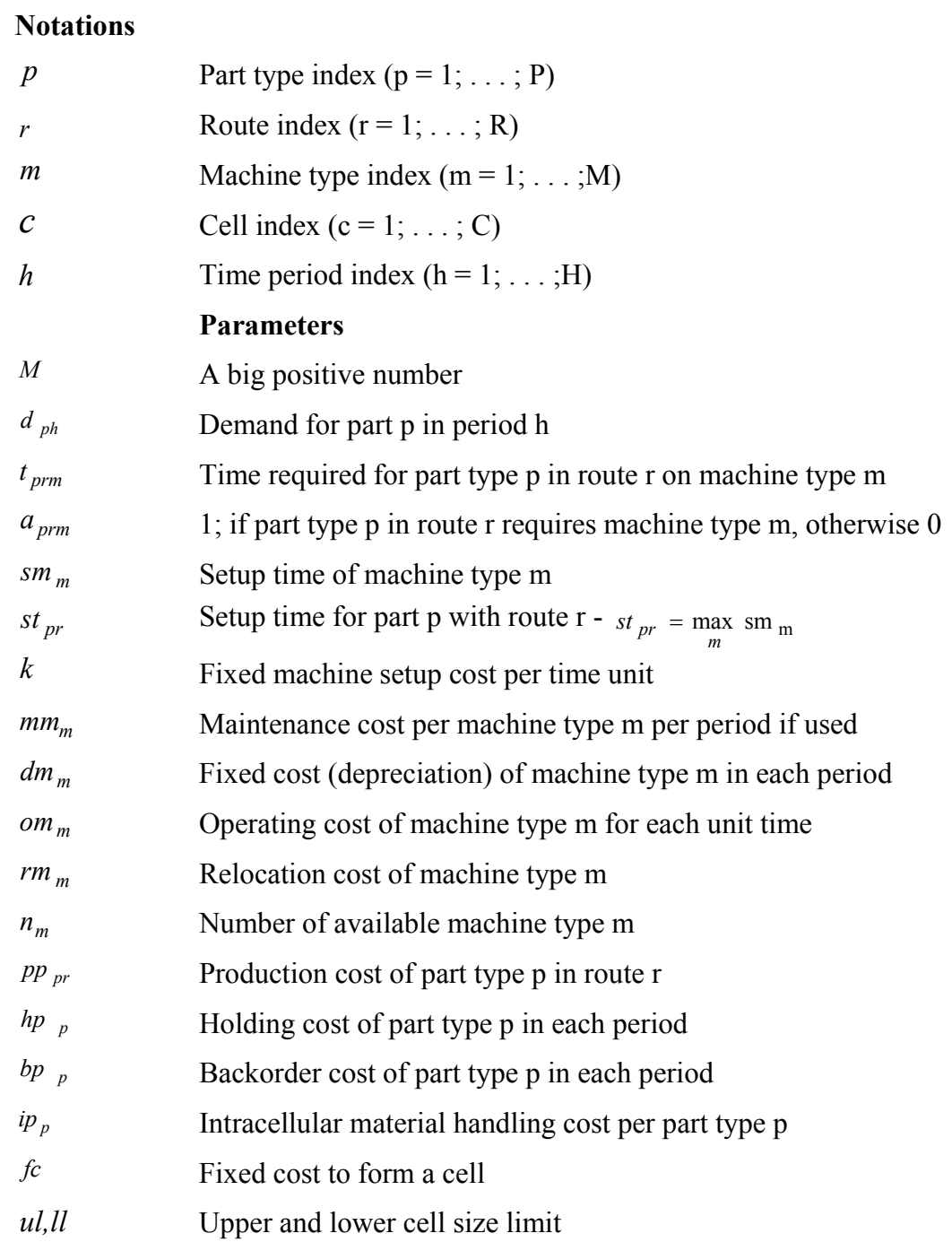


Maximum time availability of each cell in a period

$q_{1}\left(q_{2}\right) \quad$ Balancing factor for the workload of a machine (cell) $\in(0,1)$

\section{Decision variables}

$Q_{\text {prch }} \quad$ Quantity of part type $\mathrm{p}$ produced with route $\mathrm{r}$ in cell $\mathrm{c}$ and period $\mathrm{h}$

$Z_{\text {prch }} \quad 1$ if $Q_{\text {prch }}>0$; otherwise 0 (Integer)

$I_{p h} \quad$ Inventory of part type $\mathrm{p}$ at the start of period $\mathrm{h}$

$B_{p h} \quad$ Backorder of part type $\mathrm{p}$ at the start of period $\mathrm{h}$

$C_{\text {prch }} \quad$ Capacity requirement to produce $\mathrm{Q}$ units of product $\mathrm{p}$ in route $\mathrm{r}$, cell $\mathrm{c}$ and period $\mathrm{h}$

$N_{m c h} \quad$ Number of machine type $\mathrm{m}$ in cell c and period h (Integer)

$X_{c h} \quad 1$ if cell $\mathrm{c}$ is formed in period $\mathrm{h}$ (Binary)

\subsection{Mathematical model}

The integrated non-linear mathematical model is presented below.

$$
\begin{aligned}
& \min \sum_{p}^{\mathrm{P}}\left(h_{p} * \sum_{h}^{\mathrm{H}} I_{p h}+b_{p} * \sum_{h}^{\mathrm{H}} B_{p h}\right)+\sum_{p}^{\mathrm{P}} \sum_{r}^{\mathrm{R}}\left(p_{p r} * \sum_{c}^{\mathrm{C}} \sum_{h}^{\mathrm{H}} Q_{p r c h}\right) \\
& +\sum_{m}^{\mathrm{M}} \sum_{p}^{\mathrm{P}} \sum_{r}^{\mathrm{R}} \sum_{c}^{\mathrm{C}} \sum_{h}^{\mathrm{H}}\left(o_{m} * a_{p r m} * C_{p r c h} * N_{m c h}\right) \\
& +\sum_{m}^{\mathrm{M}} H * d m_{m} *_{m}+\sum_{m}^{M} \sum_{c}^{C} \sum_{h}^{H} m m_{m} * N_{m c h} \\
& +\sum_{p}^{\mathrm{P}} \sum_{r}^{\mathrm{R}} \sum_{c}^{\mathrm{C}} \sum_{h}^{\mathrm{H}} \sum_{m}^{M}\left(K^{*} s m_{m} * a_{p r m} * Z_{p r c h} * N_{m c h}\right) \\
& \left.+\sum_{m}^{M}\left(r m_{m} * \sum_{h=1}^{1} \sum_{c}^{C} N_{m c h}+\sum_{h=H}^{H} \sum_{c}^{C} N_{m c h}+\sum_{h=2}^{H}\left|\sum_{c}^{C} N_{m c h}-\sum_{c}^{C} N_{m c h-1}\right|\right)\right) \\
& +\sum_{h}^{H} \sum_{c}^{C} f_{c} * X_{c h}+\sum_{p}^{P} \sum_{r}^{R}\left(i p_{p} *\left(\sum_{m}^{M} a_{p r m}+1\right) * \sum_{c}^{C} \sum_{h}^{H} Q_{p r c h}\right)
\end{aligned}
$$

\section{Constraints:}

$$
\begin{aligned}
& \sum_{h}^{\mathrm{H}} \sum_{c}^{\mathrm{C}} \sum_{r}^{\mathrm{R}} Q_{p r c h}=\sum_{h}^{H} d_{p h} ; \forall p=1, \ldots, P \\
& I_{p, h=1}=0 ; \forall p=1, \ldots, P \\
& B_{p, h=1}=0 ; \forall p=1, \ldots, P \\
& I_{p h}-B_{p h}=\sum_{c}^{C} \sum_{r}^{R} Q_{p r c, h-1}-d_{p, h-1}+I_{p, h-1}-B_{p, h-1} ; \forall p=1, \ldots, P, h=2, \ldots, H \\
& \sum_{p}^{P} \sum_{r}^{R} Q_{p r c h}{ }^{*} t_{p r m} \\
& N_{m c h} \geq q_{1}{ }^{*} \sum_{p}^{P} \sum_{r}^{R} C_{p r c h} * X_{c h} ; \forall m=1, \ldots, M, c=1, \ldots, C, h=1, \ldots, H \\
& \sum_{p}^{P} \sum_{r}^{R} C_{p r c h} \geq q_{2}{ }^{*} t^{*} X_{c h} ; \forall c=1, \ldots, C, h=1, \ldots, H \\
& \sum_{p}^{P} \sum_{r}^{R}\left(C_{p r c h}+s t_{p r} * Z_{p r c h}\right) \leq t c ; \forall c=1, \ldots, C, h=1, \ldots, H \\
& C_{p r c h} \geq \frac{Q_{p r c h}{ }^{*} t_{p r m}}{N_{m c h}} ; \forall p=1, \ldots, P, r=1, \ldots, R, m=1, \ldots, M, c=1, \ldots, C, h=1, \ldots, H \\
& \sum_{c}^{C} N_{m c h} \leq n_{m} ; \forall m=1, \ldots, M, h=1, \ldots, H \\
& \sum_{m}^{M} N_{m c h} \leq u l ; \forall c=1, \ldots, C, h=1, \ldots, H \\
& \sum_{m}^{M} N_{m c h} \geq l l * X_{c h} ; \forall c=1, \ldots, C, h=1, \ldots, H
\end{aligned}
$$




$$
\begin{aligned}
& 218 \\
& \sum_{m}^{M} N_{m c h} \leq M * X_{c h} ; \forall c=1, \ldots, C, h=1, \ldots, H \\
& \sum_{m}^{M} N_{m c h} \geq X_{c h} ; \forall c=1, \ldots, C, h=1, \ldots, H \\
& Q_{p r c h} \leq M * Z_{p r c h} ; \forall p=1, \ldots, P, r=1, \ldots, R, c=1, \ldots, C, h=1, \ldots, H \\
& Z_{p r c h} \leq Q_{p r c h} ; \forall p=1, \ldots, P, r=1, \ldots, R, c=1, \ldots, C, h=1, \ldots, H \\
& X_{c-1, h} \geq X_{c h} ; \forall c=1, \ldots, C, h=1, \ldots, H \\
& X_{c h}, Z_{p r c h}: \text { Binary } \\
& N_{m c h}: \text { Integer } \\
& Q_{p r c h}, C_{p r c h}, I_{p h}, B_{p h} \geq 0
\end{aligned}
$$

The objective function of the model consists of several cost terms. (1a) shows part holding and backorder costs and internal production cost. (1b) is machine operating cost, (1c) is fixed and maintenance costs respectively and (1d) shows machine setup cost. (1e) represents machine relocation cost from depot to cells, cells to depot and between cells, and finally (1f) is cell forming and material handling costs respectively.

Eq. (2) is the balance between demand and internal production, and enforces the system to be empty at the end. Eq. (3) and Eq. (4) show the inventory system is empty at the start point. Eq. (5) shows the balance between production quantity, backorder, inventory and demand in two subsequent periods and shows part demand can be satisfied by internal production, backorder and/or inventory from the previous period.

Each machine must work at least $q_{1}$ portion of its cell operating time. This constraint balances workload between machines and applies by inequality (6). Like Eq. (6), Eq. (7) enforces workload balance between cells. In both inequalities, $q_{1}$ and $q_{2} \in(0,1)$. Inequality (8) ensures time-capacity limitation of each cell. Regarding production line approach, the line speed is equal to the slowest station. This case is defined in inequality (9) that shows the relationship between the number of machines, the requirement capacity, and the production quantity in a station. Inequality (10) ensures that the maximal availability of machines is not violated.

Minimum and maximum number of machines in every cell are considered by constraints (11) and (12). (13) and (14) are logical Inequalities which guarantee that number of machines in a particular cell can be positive only if the related cell is formed and vice versa. (15) and (16) ensure that $Z_{\text {prch }}$ are calculated based on $Q_{\text {prch }}$ and vice versa. (17) enforces that cells should be formed in order. Terms (18) to (20) are the logical binary, non-negativity integer or non-negativity necessities on the decision variables.

\subsection{Features and contributions of the model}

Capacity calculation: In all related papers, the capacity constraint is separately defined for each machine whereas according to operation sequences and resource limitations, more time and capacity is needed in each cell to produce the quantities. In this paper, the required capacity and the number of required machines in each cell are defined as decision variables that are calculated according to flow shop perspective.

Balance workload among machines in a cell: The proposed model solves a multi-product line balancing problem and tries to approach the workload of each station. Workload of each machine cannot be less than a predetermined value that is a percentage $\left(q_{1}\right)$ of cell operating time.

Balance workload between cells: workload of each cell cannot be less than a predetermined value that is a percentage of period time availability $\left(q_{2}\right)$. 
Independent cells: In some systems such as pharmaceutical, medical device manufacturing and food, independent cell configuration is inevitable. They are considered to be independent, inter-cell transfer of products is not allowed and each dedicated cell is responsible for the production of only one family. In this type of configuration the independent cell team is responsible for scheduling, production, maintenance and quality assurance of their own cell (Askin, 2013).

Alternate routings: It is defined in terms of the possible routes (machines) that can be used to produce a part.

Lot splitting: It means production of a part can be split into more than one route within the same cell or in different cells.

\subsection{Linearization of the model}

(1b), (1d) and (1e) in the objective function, and inequalities (6) and (9) in the model are non-linear.

(1d) is the product of a binary and an integer variable that can be linearized by introducing non-negative variable $Z N_{\text {prmch }}$ that shows number of machine type $\mathrm{m}$ used in cell $\mathrm{c}$ and period $\mathrm{h}$ to produce part $\mathrm{p}$ with route $\mathrm{r}$; and adding the following constraint:

$$
Z N_{\text {prmch }}>=N_{\text {mch }}-M *\left(1-Z_{\text {prch }}\right) ; \forall p=1, . ., P, r=1, . ., R, m=1, \ldots, M, c=1, \ldots, C, h=2, \ldots, H
$$

The non-linear absolute component (1e) can be linearized by introducing non-negative variables $K_{m c h}$. So the term $\left|N_{m c h}-N_{m c h-1}\right|$ can be replaced by $K_{m c h}$. The following constraints also should be added to the model:

$$
\begin{aligned}
& N_{m c h}-N_{m c h-1}<=K_{m c h} ; \forall m=1, \ldots, M, c=1, \ldots, C, h=2, \ldots, H \\
& N_{m c h}-N_{m c h-1}>=-K_{m c h} ; \forall m=1, \ldots, M, c=1, \ldots, C, h=2, \ldots, H \\
& K_{m c h}>=0 ; \forall m=1, \ldots, M, c=1, \ldots, C, h=1, \ldots, H
\end{aligned}
$$

In inequality (6), $X_{c h} * N_{m c h}$ is replaces by $N_{m c h}$ because of $X_{c h} * N_{m c h}=N_{m c h}$.

Equation (9) is replaced with the following constraints:

$$
\begin{aligned}
& C_{p r c h} * N_{m c h} * a_{p r m}>=Q_{p r c h} * t_{p r m} ; \forall p=1, \ldots, P, \forall r=1, \ldots, R, m=1, \ldots, M, c=1, \ldots, C, h=1, \ldots, H \\
& C_{p r c h} * N_{m c h} * a_{p r m}<=Q_{p r c h} * t_{p r m}+M\left(1-y_{p r m c h}\right) ; \forall p=1, \ldots, P, \forall r=1, \ldots, R, m=1, \ldots, M, c=1, \ldots, C, h=1, \ldots, H \\
& \sum_{m=1}^{M} a_{p r m} * y_{p r m c h}=1 ; \forall p=1, \ldots, P, \forall r=1, \ldots, R, c=1, \ldots, C, h=1, \ldots, H \\
& C_{p r c h} \leq M * Q_{p r c h} ; \forall p=1, \ldots, P, \forall r=1, \ldots, R, c=1, \ldots, C, h=1, \ldots, H
\end{aligned}
$$

When $y_{\text {prmch }}$ is a binary variable and is 1 when machine $\mathrm{m}$ in cell $\mathrm{c}$ and period $\mathrm{h}$ for product $\mathrm{p}$ with route $r$ is bottleneck.

In (1b), (6) and (9), $C_{\text {prch }} * N_{m c h}$ are the common non-linear term that can be linearized as follow:

Step 1: Introducing binary variables $X N_{i m c h}$ and the following constraints:

$$
\begin{aligned}
& N_{m c h}=\sum_{i=1}^{I_{m}} i * X N_{\text {imch }} \\
& I_{m}=\operatorname{Min}\left\{n_{m}, u l\right\} \\
& \sum_{i=1}^{I} X N_{\text {imch }} \leq 1 \\
& X N_{\text {imch }}: \text { binary }
\end{aligned}
$$

After substituting the variables, $(1 \mathrm{~b})$ is as follow:

$$
\sum_{m}^{\mathrm{M}} \sum_{p}^{\mathrm{P}} \sum_{r}^{\mathrm{R}} \sum_{c}^{\mathrm{C}} \sum_{h}^{\mathrm{H}}\left(o m_{m} * a_{p r m} * N_{m c h} * C_{p r c h}\right)=\sum_{m}^{\mathrm{M}} \sum_{p}^{\mathrm{P}} \sum_{r}^{\mathrm{R}} \sum_{c}^{\mathrm{C}} \sum_{h}^{\mathrm{H}} \sum_{i}^{I_{m}}\left(o m_{m} * a_{p r m} * i * X N_{i m c h} * C_{p r c h}\right) .
$$

And the constraints are as follow: 


$$
\begin{aligned}
& C_{p r c h} * a_{p r m} * \sum_{i=1}^{I}\left(i * X N_{i m c h}\right) \geq Q_{p r c h} * t_{p r m} ; \forall p=1, \ldots, P, \forall r=1, \ldots, R, m=1, \ldots, M, c=1, \ldots, C, h=1, \ldots, H \\
& C_{p r c h} * a_{p r m} * \sum_{i=1}^{I}\left(i * X N_{\text {imch }}\right) \leq Q_{p r c h} * t_{p r m}+M\left(1-y_{\text {prmch }}\right) ; \forall p=1, \ldots, P, \forall r=1, \ldots, R, m=1, \ldots, M, c=1, \ldots, C, h=1, \ldots, H \\
& \sum_{p}^{P} \sum_{r}^{R} Q_{\text {prch }} * t_{p r m} \geq q_{1} * \sum_{i=1}^{I}\left(i * X N_{\text {imch }}\right) * \sum_{p}^{P} \sum_{r}^{R} C_{p r c h} ; \forall m=1, \ldots, M, c=1, \ldots, C, h=1, \ldots, H
\end{aligned}
$$

Step 2: $C_{\text {prch }} * X N_{\text {imch }}$ should be replaced by $X C_{\text {iprmch }}$ that are non-negative variables and the following constraints should be added to the model:

$$
\begin{aligned}
& \sum_{i}^{I} X C_{i p r m c h} \leq C_{\text {prch }} \\
& \sum_{i}^{I} X C_{i p r m c h} \leq M * \sum_{i}^{I} X N_{i m c h} \\
& \sum_{i}^{I} X C_{i p r m c h} \geq C_{p r c h}-M\left(1-X N_{i m c h}\right) \\
& X C_{\text {iprmch }} \geq 0
\end{aligned}
$$

Therefore, the linear mathematical programming model is as follows:

$$
\begin{aligned}
& \min \text { (1a) }+\sum_{m}^{\mathrm{M}} \sum_{p}^{\mathrm{P}} \sum_{r}^{\mathrm{R}} \sum_{c}^{\mathrm{C}} \sum_{h}^{\mathrm{H}} \sum_{i}^{I}\left(o m_{m} * a_{p r m} * i^{*} X C_{\text {iprmch }}\right)+(1 \mathrm{c}) \\
& +\sum_{p}^{\mathrm{P}} \sum_{r}^{\mathrm{R}} \sum_{c}^{\mathrm{C}} \sum_{h}^{\mathrm{H}} \sum_{m}^{M}\left(K^{*} S M_{m} * a_{p r m} * Z N_{p r m c h}+\sum_{m}^{M}\left(r m_{m} * \sum_{h=1}^{1} \sum_{c}^{C} N_{m c h}+\sum_{h=H}^{H} \sum_{c}^{C} N_{m c h}+\sum_{h=2}^{H} \sum_{c}^{C} K_{m c h}\right)+(1 \mathrm{f})\right.
\end{aligned}
$$

Constraints (2)-(5), (7), (8), (10)-(18), (20) and:

$$
\begin{aligned}
& N_{m c h}-N_{m c h-1}<=K_{m c h} ; \forall m=1, \ldots, M, c=1, \ldots, C, h=2, \ldots, H \\
& N_{m c h}-N_{m c h-1}>=-K_{m c h} ; \forall m=1, \ldots, M, c=1, \ldots, C, h=2, \ldots, H \\
& \sum_{m=1}^{M} a_{p r m} * y_{p r m c h}=1 ; \forall p=1, \ldots, P, \forall r=1, \ldots, R, c=1, \ldots, C, h=1, \ldots, H \\
& \sum_{i}^{I} a_{p r m} * i^{*} X C_{i p r m c h} \geq Q_{p r c h} * t_{p r m} ; \forall p=1, \ldots, P, r=1, \ldots, R, m=1, \ldots, M, c=1, \ldots, C, h=1, \ldots, H \\
& \sum_{i}^{I} a_{p r m} *^{*} X C_{i p r m c h} \leq Q_{p r c h} * t_{p r m}+M *\left(1-y_{p r m c h} ; ; \forall p=1, \ldots, P, r=1, \ldots, R, m=1, \ldots, M, c=1, \ldots, C, h=1, \ldots, H\right. \\
& \sum_{i}^{I} X C_{i p r m c h} \leq C_{p r c h} ; \forall p=1, \ldots, P, \forall r=1, \ldots, R, m=1, \ldots, M, c=1, \ldots, C, h=1, \ldots, H \\
& \sum_{i}^{I} X C_{i p r m c h} \leq M * \sum_{i}^{I} X N_{i m c h} ; \forall m=1, \ldots, M, c=1, \ldots, C, h=1, \ldots, H \\
& \sum_{i}^{I} X C_{i p r m c h} \geq C_{p r c h}-M\left(1-X N_{i m c h}\right) ; \forall i=1, \ldots, I_{m}, m=1, \ldots, M, c=1, \ldots, C, h=1, \ldots, H \\
& N_{m c h}=\sum_{i=1}^{I} i^{*} X N_{i m c h} ; \forall i=1, . ., I, m=1, \ldots, M, c=1, \ldots, C, h=1, \ldots, H \\
& I=M i n\left\{N_{m}, U L\right\} ; \forall m=1, \ldots, M \\
& \sum_{i=1}^{I} X N_{i m c h} \leq 1 ; \forall i=1, . ., I, m=1, \ldots, M, c=1, \ldots, C, h=1, \ldots, H \\
& C_{p r c h} \leq M * Q_{p r c h} ; \forall p=1, \ldots, P, \forall r=1, \ldots, R, c=1, \ldots, C, h=1, \ldots, H \\
& K_{m c h}>=0 ; \forall m=1, \ldots, M, c=1, \ldots, C, h=1, \ldots, H \\
& X C_{\text {prmch }} \geq 0 \\
& X N_{i m c h}: b i n a r y
\end{aligned}
$$




\section{Three-phase heuristic approach}

Although the non-linear proposed model linearized without much difficulty but linearization increases the number of variables and constraints and it would take too long to solve even small problems. We directly solved some small problems using Lingo and the results were used to test the quality of the proposed heuristic algorithm. The algorithm can solve real problems in a reasonable time but similar to any other heuristic algorithms, optimality of the solution is not guaranteed. We used Visual C++ environment to program the algorithm that calls Lingo DLL (Dynamic Link Library). @POINTER functions also allow to transfer data directly through shared memory locations.

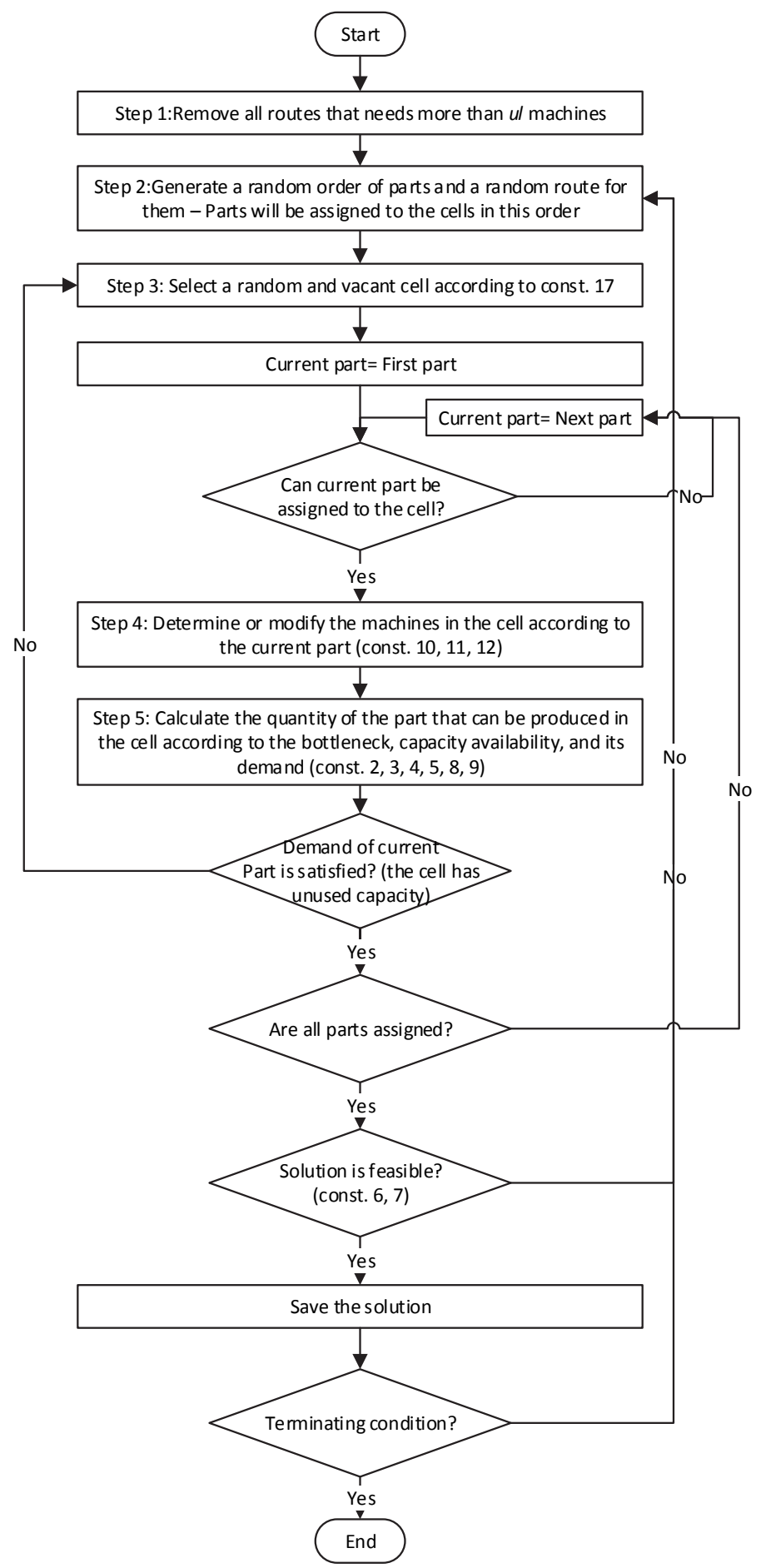

Fig. 1. Flow chart of phase 1 
The first phase of the algorithm is to find a feasible solution for the problem. The second phase generates the other feasible neighborhood solutions and the third phase improves them. The main purpose of phase 1 is machine assignment to the cells but according to the cell and machine workload balance constraints, it cannot be done without production quantity values. Phase 1 (Fig. 1) starts with a random order of parts and a random route for each part. Parts are assigned to a random selected cell (constraint 17) in order. Then according to the existing machines in the cell and constraints 10, 11, 12 the number of machines is determined. Quantity of each part is calculated after (constraints 2, 3, 4, 5, $8,9)$. Finally, feasibility of the solution is checked according to the constraints 6 and 7 . The following is a sample iteration of Phase 1 for problem 8 based on data in Tables 4-8:

Step 1: All parts need maximum $6(=\mathrm{ul})$ machines.

Step 2: P2R2; P5R1; P3R1; P6R2; P1R1; P4R2

Step 3: Cell 1 period 2

Step 4: Table 1 lists the different alternatives of machines in the cell according to P2R2. The randomly selected alternative is number 2 .

\section{Table 1}

Different alternatives for machine assignment-part 2 route 2

\begin{tabular}{|c|c|c|c|c|c|c|c|c|c|c|}
\hline \multirow{2}{*}{ Alt. } & \multicolumn{5}{|c|}{ No of machines } & \multirow[b]{2}{*}{ M6 } & \multirow[b]{2}{*}{ M7 } & \multirow{2}{*}{$\begin{array}{l}\text { Cycle } \\
\text { time }\end{array}$} & \multirow{2}{*}{$\begin{array}{l}\text { No of machines } \\
\text { in cell }\end{array}$} & \multirow{2}{*}{ Desc. } \\
\hline & M1 & M2 & M3 & M4 & M5 & & & & & \\
\hline 1 & & 1 & & & 1 & 1 & 1 & 6 & $4<\mathrm{ul}$ & Feasible \\
\hline 2 & & 1 & & & 1 & 1 & 2 & 5 & $5<\mathrm{ul}$ & Feasible \\
\hline 3 & & 2 & & & 1 & 1 & 2 & 4 & $6=\mathrm{ul}$ & Feasible \\
\hline 4 & & 2 & & & 1 & 2 & 2 & 3 & $7>\mathrm{ul}$ & Infeasible \\
\hline
\end{tabular}

Step 5: The quantity is $\operatorname{Min}\left\{\frac{8000-12 \text { (setup time) }}{5 \text { (cycle time) }}, 940(=400+210+330)\right\}=940$ and unused capacity of the cell is $8000-940 * 5-12=3288$.

Demand for item P2R2 is produced. The algorithm checks the next item P5R1.

Step 4: Table 2 shows the alternatives considering P5R. Option 1 is the only feasible solution.

Table 2

Different alternatives for machine assignment-part 5 route 1

\begin{tabular}{lllllllllll}
\hline \multirow{2}{*}{ Alt. } & M1 & M2 & M3 & M4 & M5 & M6 & M7 & $\begin{array}{l}\text { Cycle } \\
\text { time }\end{array}$ & $\begin{array}{c}\text { No of machines } \\
\text { in cell }\end{array}$ & Desc. \\
\hline 1 & 1 & 1 & & & 1 & 1 & 2 & 5 & $6=$ ul & Feasible \\
2 & 1 & 1 & & & 1 & 2 & 2 & 4 & $7>$ ul & Infeasible \\
\hline
\end{tabular}

Step 5: The quantity for P5R1 is $\operatorname{Min}\left\{\frac{3288-10 \text { (setup time) }}{5 \text { (cycle time) }}, 3060(=1100+950+1010)\right\}=655.6$ and unassigned capacity is 0 . The algorithm selects the next cell to assign the rest demand of P5R1 and other items.

Phase 2 generates all neighborhood solutions of the feasible solution found in phase 1 that is defines by swapping two cells in a same period. According to the model, all neighborhood solutions generated are always feasible and number of them depends on the number of cells in each period. For instance, if there are 3,2, and 2 cells in period 1,2, and 3 respectively, number of neighborhood solutions is 5 $(3+1+1)$. According to the neighborhood definition, the only difference between their objective function is machine relocation cost item. The cost element is calculated for the neighborhood solutions and the least solution(s) is sent to Phase 3. 


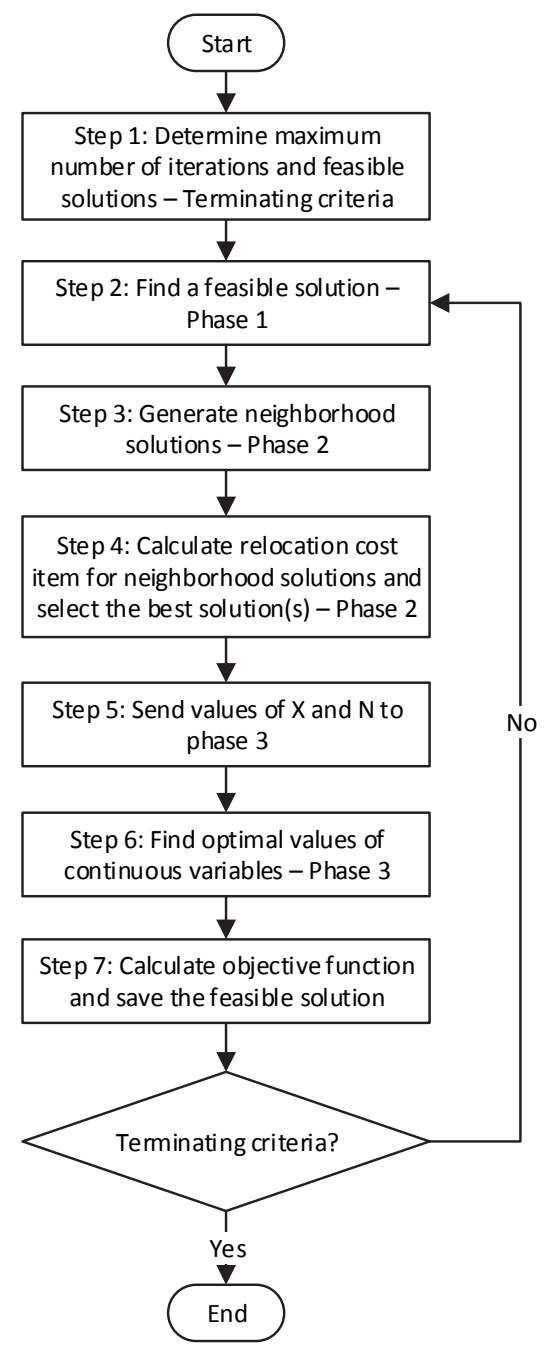

Fig. 2. The steps of three-phase algorithm

Phase 3 sends $X_{c h}$ and $N_{m c h}$ of the found solution(s) to Lingo to find the optimal values for $Q_{\text {prch }}, C_{\text {prch }}, Z_{\text {prch }}, I_{p h}$ and $B_{p h}$ for each feasible solution. So, this phase does not relocate any machines or change number of occupied cells. At the end, phase 3 returns the best solution. The steps of the algorithm are represented in Fig. 2.

\section{Numerical experiments and discussion}

To evaluate the computational performance of the proposed algorithm, 15 problems, shown in Table 3 are considered. Since the mathematical model is different from those reported in the research literature, data sets of the problems were developed by the authors. All problems were tested and have feasible area (optimal solution). All test problems are conducted on a PC with Intel Core i7-6700 3.4 GHz processor and 16GB DDR4 memory. The objective function values obtained in this paper cannot be compared to the previous studies because of the new proposed model, different cost components, and manufacturing attributes involved. The input data set for the small problems (1-8) are in tables 4 to 8 . The data consists of six part types each having two different routings, seven machine types, and three periods. Maximum number of cells is three and balance coefficient for machine $\left(q_{1}\right)$ and cell $\left(q_{2}\right)$ is 0.4 and 0.5 . Problem 1 for instance shows the problem with first three part types, and first two periods of the data set. We compared the obtained objective values from the proposed algorithm (maximum 
$10,000,000$ iterations and 100 feasible solutions as the terminating criteria, any met first) and Lingo software for the mentioned small problems in Table 9.

Table 3

Problem information

\begin{tabular}{|c|c|c|c|c|c|c|c|c|c|}
\hline $\begin{array}{l}\text { Pr. } \\
\text { type }\end{array}$ & $\begin{array}{l}\text { Pr. } \\
\text { No. }\end{array}$ & $\begin{array}{l}\text { No of } \mathrm{Pa} . \\
\text { types }\end{array}$ & No of Ro. & $\begin{array}{l}\text { No of Ma. } \\
\text { types }\end{array}$ & No of Op. & $\begin{array}{l}\text { No of } \\
\text { Ce. }\end{array}$ & $\begin{array}{l}\text { No of } \\
\text { Pe. }\end{array}$ & $\begin{array}{l}\text { No of } \\
\text { var. }\end{array}$ & $\begin{array}{l}\text { No of } \\
\text { Con. }\end{array}$ \\
\hline \multirow{8}{*}{ 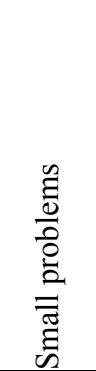 } & 1 & 3 & 2 & 7 & $2-5$ & 3 & 2 & 1338 & 1261 \\
\hline & 2 & 4 & 2 & 7 & $2-5$ & 3 & 2 & 1712 & 1551 \\
\hline & 3 & 5 & 2 & 7 & $2-5$ & 3 & 2 & 2086 & 1841 \\
\hline & 4 & 6 & 2 & 7 & $2-5$ & 3 & 2 & 2456 & 2131 \\
\hline & 5 & 3 & 2 & 7 & $2-5$ & 3 & 3 & 2010 & 1912 \\
\hline & 6 & 4 & 2 & 7 & $2-5$ & 3 & 3 & 2572 & 2347 \\
\hline & 7 & 5 & 2 & 7 & $2-5$ & 3 & 3 & 3128 & 2782 \\
\hline & 8 & 6 & 2 & 7 & $2-5$ & 3 & 3 & 3696 & 3217 \\
\hline \multirow{7}{*}{ 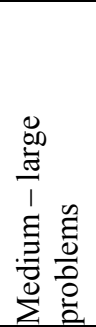 } & 9 & 12 & 2 & 8 & $2-5$ & 8 & 1 & 11848 & 5900 \\
\hline & 10 & 12 & 2 & 10 & $2-5$ & 8 & 3 & 44040 & 21960 \\
\hline & 11 & 15 & 2 & 10 & $2-5$ & 8 & 3 & 54564 & 26721 \\
\hline & 12 & 20 & 2 & 10 & $2-5$ & 9 & 3 & 81107 & 38977 \\
\hline & 13 & 25 & 2 & 10 & $2-5$ & 9 & 3 & 100837 & 47902 \\
\hline & 14 & 30 & 2 & 15 & $3-7$ & 3 & 3 & 59529 & 27646 \\
\hline & 15 & 40 & 2 & 10 & $2-5$ & 3 & 3 & 53449 & 24991 \\
\hline
\end{tabular}

Pr.: problem / Pa.: Part / Ro.:routes / Ma.: machine / Op.: operations / Ce.: cells / Pe.: periods / Var.: variables / Con.: constraints

Table 4

Part information

\begin{tabular}{lcccccc}
\hline Product & $\begin{array}{c}\text { Holding } \\
\text { cost (unit) }\end{array}$ & $\begin{array}{c}\text { Backorder cost } \\
\text { (unit) }\end{array}$ & $\begin{array}{c}\text { Intracellular } \\
\text { handling (unit) }\end{array}$ & Period 1 & $\begin{array}{c}\text { Demand } \\
\text { Period 2 }\end{array}$ & Period 3 \\
\hline P1 & 2 & 1 & 0.3 & 770 & 615 & 650 \\
P2 & 4 & 7 & 1.1 & 400 & 210 & 330 \\
P3 & 5 & 11 & 0.2 & 300 & 510 & 580 \\
P4 & 1 & 4 & 0.8 & 440 & 700 & 410 \\
P5 & 8 & 3 & 0.5 & 1100 & 950 & 1010 \\
P6 & 14 & 10 & 0.9 & 850 & 670 & 500 \\
\hline
\end{tabular}

Table 5

Machine information

\begin{tabular}{lccccc}
\hline Machine & Maximum & $\begin{array}{c}\text { Operating } \\
\text { cost (min) }\end{array}$ & $\begin{array}{c}\text { Maintenance cost } \\
\text { (period) }\end{array}$ & $\begin{array}{c}\text { Fixed cost } \\
\text { (period) }\end{array}$ & Relocation cost \\
\hline M1 & 3 & 4 & 85 & 100 & 3000 \\
M2 & 3 & 6 & 60 & 25 & 4000 \\
M3 & 3 & 1 & 110 & 85 & 500 \\
M4 & 3 & 8 & 140 & 20 & 12000 \\
M5 & 3 & 2 & 75 & 40 & 8000 \\
M6 & 3 & 4 & 35 & 50 & 9000 \\
M7 & 3 & 9 & 100 & 15 & 25000 \\
\hline
\end{tabular}


Table 6

Data for processing time and production cost

\begin{tabular}{|c|c|c|c|c|c|c|c|c|c|}
\hline \multirow{2}{*}{ Product } & \multirow{2}{*}{ Route } & \multicolumn{6}{|c|}{ Processing time } & \multirow[b]{2}{*}{ M7 } & \multirow{2}{*}{ Production cost } \\
\hline & & M1 & M2 & M3 & M4 & M5 & M6 & & \\
\hline \multirow{2}{*}{$\mathrm{P} 1$} & R1 & 0 & 4 & 0 & 0 & 6 & 3 & 0 & 5 \\
\hline & $\mathrm{R} 2$ & 3 & 0 & 0 & 0 & 2 & 3 & 0 & 3.25 \\
\hline \multirow{2}{*}{$\mathrm{P} 2$} & R1 & 0 & 0 & 0 & 0 & 6 & 4 & 8 & 7.75 \\
\hline & $\mathrm{R} 2$ & 0 & 5 & 0 & 0 & 3 & 4 & 6 & 1.25 \\
\hline \multirow{2}{*}{ P3 } & R1 & 0 & 0 & 4 & 6 & 8 & 7 & 0 & 1.75 \\
\hline & $\mathrm{R} 2$ & 0 & 0 & 4 & 6 & 0 & 4 & 0 & 9.5 \\
\hline \multirow{2}{*}{ P4 } & R1 & 0 & 8 & 0 & 0 & 6 & 5 & 0 & 4.25 \\
\hline & $\mathrm{R} 2$ & 0 & 6 & 0 & 0 & 3 & 5 & 0 & 4.5 \\
\hline \multirow{2}{*}{ P5 } & R1 & 3 & 4 & 0 & 0 & 3 & 5 & 0 & 9.75 \\
\hline & $\mathrm{R} 2$ & 4 & 0 & 0 & 0 & 4 & 7 & 0 & 4.75 \\
\hline \multirow{2}{*}{ P6 } & R1 & 0 & 0 & 6 & 4 & 4 & 5 & 3 & 3.75 \\
\hline & $\mathrm{R} 2$ & 0 & 5 & 0 & 0 & 7 & 9 & 6 & 8.25 \\
\hline
\end{tabular}

Table 7

Data for operations and routes setup time

\begin{tabular}{|c|c|c|c|c|c|c|c|c|c|}
\hline \multirow{2}{*}{ Product } & \multirow{2}{*}{ Route } & \multicolumn{6}{|c|}{ Operation setup time } & \multirow[b]{2}{*}{ M7 } & \multirow{2}{*}{ Route setup time } \\
\hline & & M1 & M2 & M3 & M4 & M5 & M6 & & \\
\hline \multirow{2}{*}{ P1 } & R1 & 0 & 5 & 0 & 0 & 2 & 5 & 0 & 5 \\
\hline & $\mathrm{R} 2$ & 8 & 0 & 0 & 0 & 5 & 8 & 0 & 8 \\
\hline \multirow{2}{*}{$\mathrm{P} 2$} & $\mathrm{R} 1$ & 0 & 0 & 0 & 0 & 8 & 7 & 4 & 8 \\
\hline & $\mathrm{R} 2$ & 0 & 10 & 0 & 0 & 1 & 2 & 12 & 12 \\
\hline \multirow{2}{*}{ P3 } & $\mathrm{R} 1$ & 0 & 0 & 2 & 12 & 13 & 1 & 0 & 13 \\
\hline & $\mathrm{R} 2$ & 0 & 0 & 4 & 3 & 0 & 6 & 0 & 6 \\
\hline \multirow{2}{*}{ P4 } & R1 & 0 & 8 & 0 & 0 & 4 & 3 & 0 & 8 \\
\hline & $\mathrm{R} 2$ & 0 & 6 & 0 & 0 & 3 & 5 & 0 & 6 \\
\hline \multirow{2}{*}{ P5 } & $\mathrm{R} 1$ & 5 & 1 & 0 & 0 & 1 & 10 & 0 & 10 \\
\hline & $\mathrm{R} 2$ & 7 & 0 & 0 & 0 & 2 & 7 & 0 & 7 \\
\hline \multirow{2}{*}{ P6 } & R2 & 0 & 0 & 9 & 2 & 12 & 7 & 10 & 12 \\
\hline & R3 & 0 & 11 & 0 & 0 & 7 & 5 & 8 & 11 \\
\hline
\end{tabular}

\section{Table 8}

\section{Cell information}

\begin{tabular}{ll}
\hline Forming cost for each cell & 50000 \\
Max machines in each cell & 6 \\
Min machines in each cell & 3 \\
Capacity of each cell/machine (min) & 8000 \\
\hline
\end{tabular}

\section{Table 9}

Comparison of the suggested three-phase approach with Lingo - small problems

\begin{tabular}{lccccc}
\hline \multirow{2}{*}{ Pr. No. } & \multicolumn{2}{c}{ Lingo } & \multicolumn{2}{c}{ Proposed algorithm } & \multirow{2}{*}{ Gap (\%) } \\
\cline { 2 - 5 } & CPU time & Obj. fun. & CPU time & Best obj. fun. & 0 \\
1 & $00: 03: 14$ & 435971 & $00: 24: 55$ & 435971 & 0 \\
3 & $00: 42: 35$ & 593463 & $00: 25: 36$ & 893463 & 3 \\
4 & $03: 27: 52$ & 818367 & $00: 26: 58$ & 1065306 & 3 \\
5 & $08: 11: 19$ & 1034278 & $00: 27: 09$ & 635553 & 0 \\
6 & $02: 41: 06$ & 635553 & $00: 28: 02$ & 801086 & 1 \\
7 & $03: 35: 17$ & 793154 & $00: 28: 36$ & 1054830 & 2 \\
8 & $08: 07: 50$ & 1034147 & $00: 29: 20$ & 1636912 & 3 \\
\hline
\end{tabular}

To analyze the performance of the proposed algorithm for medium-large size problems, we used Lingo but is not able to find the optimal solution for any of them, so we recorded the feasible solution and/or objective bound after 5 hours for each problem. The proposed algorithm also applied to solve them and the first feasible solution, time elapsed to find it, number of feasible solutions in 2 hours, and the best feasible solution are recorded to make a comparison with Lingo's results (Table 10). 
Table 10

Comparison of the suggested three-phase approach with Lingo - medium / large problems

\begin{tabular}{lllllll}
\hline \multirow{2}{*}{ Pr. No. } & \multicolumn{2}{c}{ Lingo } & \multicolumn{4}{c}{ Proposed algorithm } \\
& Feasible solution & Obj. bound & First Fea. Sol. & Elapsed time & No. of Fea Sol. & Best Fea. Sol. \\
\hline 9 & 1294761 & 477677 & 1618451 & $00: 07: 11$ & 31 & 1379729 \\
10 & - & 1297494 & 3847320 & $00: 09: 25$ & 22 & 3151340 \\
11 & - & 1619717 & 4695752 & $00: 13: 02$ & 14 & 4086243 \\
12 & - & 1854553 & 5489047 & $00: 14: 51$ & 5 & 4425819 \\
$13^{*}$ & - & - & 5972338 & $00: 19: 39$ & 2 & 5368535 \\
14 & - & 568343 & 3426529 & $00: 11: 42$ & 12 & 2870403 \\
15 & - & 601782 & 3749148 & $00: 10: 33$ & 13 & 3093047 \\
\hline
\end{tabular}

*Ran out of memory / Fea.: feasible; Sol.: solution

It is evident that the required computational times increase as the problems (variables and constraints) are increased in both Lingo and the proposed algorithm but increasing rates are different. Tables 9 and 10 show that just for problem 1 that is the smallest one, Lingo is more effective than the algorithm. The gap between the solutions along with CPU time in Table 9 clearly shows the efficiency of the algorithm. Table 10 shows that the algorithm was able to find some feasible solutions in reasonable amount of time while Lingo could not. As the optimal solution of problems in the table are unknown, it is not possible to calculate and analyze gap. The number of feasible solutions strongly depends on $q_{1}$ and $q_{2}$ values. Table 11 shows the result of phase 1 for problem 8 for 10,000,000 iterations that takes 33 minutes approximately. According to the table, the best strategy is to determine the maximum number of required feasible solutions and iterations as terminating criteria. To show the trend of the objective function improvement, the algorithm was implemented to solve problem 8 and first 50 feasible solutions are presented in Fig. 3 sorted by objective function value. As Table 11 shows, the algorithm is more efficient with smaller values for $q_{1}$ and $q_{2}$ whereas in Lingo, the required time and the $q_{1}$ and $q_{2}$ values are independent. The values used in this paper are close to the worst case.

\section{Table 11}

Number of feasible solutions of phase 1 in $10,000,000$ iterations

\begin{tabular}{|c|c|c|}
\hline$q_{1}$ & $q_{2}$ & No. of feasible \\
\hline 0.3 & 0.4 & 847 \\
\hline 0.3 & 0.5 & 624 \\
\hline 0.3 & 0.6 & 243 \\
\hline 0.4 & 0.4 & 134 \\
\hline 0.4 & 0.5 & 64 \\
\hline 0.4 & 0.6 & 32 \\
\hline $0.5^{*}$ & 0.4 & - \\
\hline $0.5^{*}$ & 0.5 & - \\
\hline $0.5^{*}$ & 0.6 & - \\
\hline
\end{tabular}

*This problem has no feasible solution.

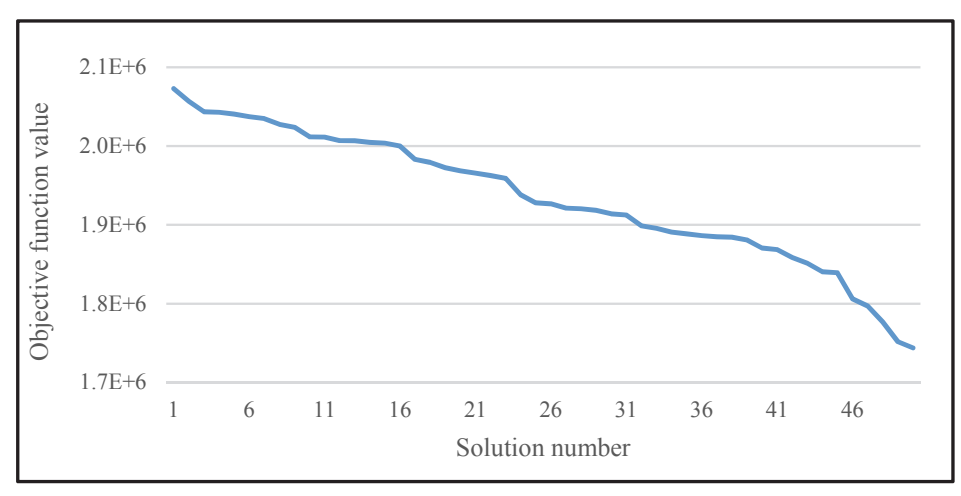

Fig. 3. Trend of improvement in problem 8

\section{Conclusion and future research}

In this paper, a new mixed integer non-linear mathematical model has been presented to design dynamic CMSs that considers CF and PP, simultaneously. The model attempts to minimize production, machine, and cell related costs and incorporates different features such as alternate routings, system reconfiguration, lot splitting, and workload balance among machines and cells are applied. For the first time, required capacity was calculated based on flow shop approach and the optimal solution for small problems found according to a multiple product line balancing problem. The proposed model belongs to the class of NP-hard problems and may not be solved using optimization packages. A three-phase heuristic algorithm was developed which could determine near-optimal solutions in reasonable amount of time in comparison with the branch and bound method for medium and large problems. The first phase could find the feasible solutions while the second phase could generate neighborhood feasible solutions, and the third phase could improve them using Lingo. For the eight out of mentioned 
problems, the algorithm found optimal and near optimal solutions and the computational efficiency was presented. For the medium and large problems, the proposed method could find some feasible solutions in a reasonable amount of time. The model can be developed by including other features, such as introducing uncertainty in a part demand, machine availability, operation time and cost coefficient, and scheduling and layout issues for future research. The model can also be improved by line balancing development. As this model is the first model that applied flow shop approach to calculate required capacity, the result can be compared with the resources in problems with job shop approach.

\section{References}

Aghajani, A., Didehbani, S. A., Kazemi, M., \& Javadian, N. (2014). A dynamic non-linear mixed integerprogramming model for the CMS design with production planning. International Journal of Industrial and Systems Engineering, 16(1), 70-87.

Aghajani-Delavar, N., Mehdizadeh, E., Torabi, S. A., \& Tavakkoli-Moghaddam, R. (2014). Design of a new mathematical model for integrated dynamic cellular manufacturing systems and production planning. International Journal of Engineering-Transactions B: Applications, 28(5), 746.

Ahkioon, S., Bulgak, A. A., \& Bektas, T. (2009a). Integrated cellular manufacturing systems design with production planning and dynamic system reconfiguration. European Journal of Operational Research, $192(2), 414-428$.

Ahkioon, S., Bulgak, A. A., \& Bektas, T. (2009b). Cellular manufacturing systems design with routing flexibility, machine procurement, production planning and dynamic system reconfiguration. International Journal of Production Research, 47(6), 1573-1600.

Aljuneidi, T., \& Bulgak, A. A. (2016). Design of Cellular Manufacturing Systems Considering Dynamic Production Planning and Worker Assignments. Journal of Mathematics and System Sciences, 6, 1-15.

Askin, R.G. \& Estrada, S. (1999). Investigation of cellular manufacturing practices. Handbook of cellular manufacturing systems, pp.25-34.

Askin, R.G. (2013). Contributions to the design and analysis of cellular manufacturing systems. International Journal of Production Research, 51(23-24), 6778-6787.

Chen, M. (2001). A model for integrated production planning in cellular manufacturing systems. Integrated Manufacturing Systems, 12(4), 275-284.

Chen, M., \& Cao, D. (2004). Coordinating production planning in cellular manufacturing environment using Tabu search. Computers \& Industrial Engineering, 46(3), 571-588.

Deep, K., \& Singh, P. K. (2016). Dynamic cellular manufacturing system design considering alternative routing and part operation tradeoff using simulated annealing based genetic algorithm. Sädhanā, 41(9), 1063-1079.

Defersha, F. M., \& Chen, M. (2008). A linear programming embedded genetic algorithm for an integrated cell formation and lot sizing considering product quality. European Journal of Operational Research, 187(1), 46-69.

Defersha, F. M., \& Chen, M. (2009). A simulated annealing algorithm for dynamic system reconfiguration and production planning in cellular manufacturing. International Journal of Manufacturing Technology and Management, 17(1-2), 103-124.

Ghodsi, R., Mostafayi, S., Mansouri, Z., \& Bakhtiari, M. (2015). Designing a Bi-objective Integrating Mathematical Model for Dynamic Sustainable Cellular Manufacturing Systems Considering Production Planning. Journal of Applied Mechanical Engineering, 4, 184.

Javadian, N., Aghajani, A., Rezaeian, J., \& Ghaneian Sebdani, M. J. (2011). A multi-objective integrated cellular manufacturing systems design with dynamic system reconfiguration. The International Journal of Advanced Manufacturing Technology, 56(1), 307-317.

Khaksar-Haghani, F., Kia, R., Javadian, N., Tavakkoli-Moghaddam, R., \& Baboli, A. (2011). A comprehensive mathematical model for the design of a dynamic cellular manufacturing system integrated with production planning and several manufacturing attributes. International Journal of Industrial Engineering \& Production Research, 22(3), 199-212.

Khannan, M. S. A., Maruf, A., Wangsaputra, R., Sutrisno, S., \& Wibawa, T. (2016, February). Cellular manufacturing system with dynamic lot size material handling. In IOP Conference Series: Materials Science and Engineering (Vol. 114, No. 1, p. 012144). IOP Publishing. 
Mahdavi, I., Aalaei, A., Paydar, M. M., \& Solimanpur, M. (2010). Designing a mathematical model for dynamic cellular manufacturing systems considering production planning and worker assignment. Computers \& Mathematics with Applications, 60(4), 1014-1025.

Mahdavi, I., Aalaei, A., Paydar, M. M., \& Solimanpur, M. (2010). Designing a mathematical model for dynamic cellular manufacturing systems considering production planning and worker assignment. Computers \& Mathematics with Applications, 60(4), 1014-1025.

Mahdavi, I., Aalaei, A., Paydar, M. M., \& Solimanpur, M. (2011). Multi-objective cell formation and production planning in dynamic virtual cellular manufacturing systems. International Journal of Production Research, 49(21), 6517-6537.

Paydar, M. M., Saidi-Mehrabad, M., \& Kia, R. (2013). Designing a new integrated model for dynamic cellular manufacturing systems with production planning and intra-cell layout. International Journal of Applied Decision Sciences, 6(2), 117-143.

Rabbani, M., Samavati, M., Ziaee, M. S., \& Rafiei, H. (2014). Reconfigurable dynamic cellular manufacturing system: A new bi-objective mathematical model. RAIRO-Operations Research, 48(1), 75-102.

Rafiee, K., Rabbani, M., Rafiei, H., \& Rahimi-Vahed, A. (2011). A new approach towards integrated cell formation and inventory lot sizing in an unreliable cellular manufacturing system. Applied Mathematical Modelling, 35(4), 1810-1819.

Raminfar, R., Zulkifli, N., Vasili, M., \& Sai Hong, T. (2013). An integrated model for production planning and cell formation in cellular manufacturing systems. Journal of Applied Mathematics, 2013.

Safaei, N., \& Tavakkoli-Moghaddam, R. (2009). Integrated multi-period cell formation and subcontracting production planning in dynamic cellular manufacturing systems. International Journal of Production Economics, 120(2), 301-314.

Sakhaii, M., Tavakkoli-Moghaddam, R., Bagheri, M., \& Vatani, B. (2016). A robust optimization approach for an integrated dynamic cellular manufacturing system and production planning with unreliable machines. Applied Mathematical Modelling, 40(1), 169-191.

Sarayloo, F., \& Tavakkoli-Moghaddam, R. (2010, August). Imperialistic competitive algorithm for solving a dynamic cell formation problem with production planning. In International Conference on Intelligent Computing (pp. 266-276). Springer Berlin Heidelberg.

Saxena, L. K., \& Jain, P. K. (2011). Dynamic cellular manufacturing systems design - a comprehensive model. The International Journal of Advanced Manufacturing Technology, 53(1-4), 11-34.

Shirazi, H., Kia, R., Javadian, N., \& Tavakkoli-Moghaddam, R. (2014). An archived multi-objective simulated annealing for a dynamic cellular manufacturing system. Journal of Industrial Engineering International, 10(2), 58.

Soolaki, M. (2012). A multi-objective integrated cellular manufacturing systems design with production planning, worker assignment and dynamic system reconfiguration. International Journal of Industrial and Systems Engineering, 12(3), 280-300.

Suer, G. A., \& Ortega, M. (1996). Flexibility considerations in designing manufacturing cells: A case study. Group technology and cellular manufacturing-methodologies and applications, 97-127.

Tavakkoli-Moghaddam, R., Safaei, N., \& Sassani, F. (2008). A new solution for a dynamic cell formation problem with alternative routing and machine costs using simulated annealing. Journal of the Operational Research Society, 59(4), 443-454.

Tavakkoli-Moghaddam, R., Sakhaii, M., \& Vatani, B. (2014). A robust model for a dynamic cellular manufacturing system with production planning. International Journal of Engineering, Transactions A: Basics, 27(4), 587-598.

Wemmerlöv, U., \& Hyer, N. L. (1989). Cellular manufacturing in the US industry: a survey of users. The International Journal of Production Research, 27(9), 1511-1530.

Wemmerlov, U., \& Johnson, D. J. (1997). Cellular manufacturing at 46 user plants: implementation experiences and performance improvements. International Journal of Production Research, 35(1), 29-49.

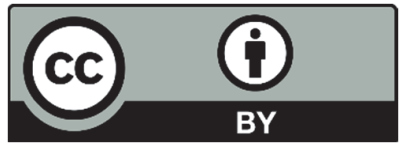

(C) 2018 by the authors; licensee Growing Science, Canada. This is an open access article distributed under the terms and conditions of the Creative Commons Attribution (CC-BY) license (http://creativecommons.org/licenses/by/4.0/). 